\title{
Inhabiting Institutions: Critical Realist Refinements to Understanding Institutional Complexity and Change
}

Organization Studies $0(0)|-2|$

(c) The Author(s) 2013

Reprints and permissions: sagepub.co.uk/journalsPermissions.nav DOI: 10.1 I77/01708406|3483805 www.egosnet.org/os

@SAGE

\section{Rick Delbridge}

Cardiff Business School, Cardiff University, UK

\section{Tim Edwards}

Cardiff Business School, Cardiff University, UK

\begin{abstract}
This paper builds on recent contributions to understanding conditions of institutional complexity by developing a theoretical framework to elaborate the interdependencies between actions, contexts and institutional logics. Our aim is to refine existing explanations of how actors inhabit complex institutional settings. Drawing on a critical realist ontology, we treat agency and structure as analytically distinct phenomena to advance our understanding of conditioned action. This is subject to relational analysis in order to explain the structural conditioning that shapes particular socio-historical contexts, the potential 'action options' contained within these contexts and the processes through which actors draw upon these. This reading of institutional reproduction and transformation allows us to reassess the 'paradox of embedded agency' by advancing understanding of the historically grounded and multilevel nature of structures and agency in institutional processes. Our approach offers conceptual refinements, a new sensitizing framework and methodological insights to guide studies of the ways actors inhabit complex institutional settings.
\end{abstract}

\section{Keywords}

conditioned action, critical realism, embedded agency, new institutionalism, inhabited institutions, institutional logics

\section{Introduction}

There have been long-standing concerns among institutional theorists that the field has bifurcated along micro-/macro- lines. Recent attempts to come to terms with the implications of institutional complexity, where several institutional logics are potentially in play at the same time, has returned 
attention to questions of agency and structure in institutional analyses. Drawing on Friedland and Alford's (1991) conception of society as an inter-institutional system, human agency is conceived in the context of 'individuals competing and negotiating, organizations in conflict and coordination, and institutions in contradiction and interdependence' (Friedland \& Alford, 1991, pp. 240 241). The concept of logics is valuable because it is built upon an integrated conceptual architecture that works at three levels of analysis (i.e. the individual, the organizational and the societal) (Friedland \& Alford, 1991; Thornton \& Ocasio, 2008; Thornton, Ocasio \& Lounsbury, 2012). This offers the building blocks to integrate micro-processes of agency with higher-order levels of analysis that relate to institutional complexity (Greenwood, Raynard, Kodeih, Micelotta \& Lounsbury, 2011). The institutional logics concept has the advantage of drawing attention to the multiple societal sectors that shape the cognitions and behaviours of actors - the market, state, family, religions, corporation, professions and community - while also integrating agency within a multi-level mode of analysis (Thornton et al., 2012).

However, the full explanatory potential of Friedland and Alford's (1991) template remains untapped. As Dunn and Jones (2010, p. 126) remark, 'there has been relatively little theoretical or empirical work that adjudicates between different instantiations of and attention to logics'. We would suggest that, while the logics concept signals the existence of multiple institutional sources of action (Greenwood et al., 2011), more work is needed to explain the dynamics of plural social orders. Over the years, the dominant approach of institutional scholars has been a 'downward' reading of action, which treats agency as a second-order concept; the result is an ontology that prioritizes structure over agency (Leca \& Naccache, 2006). Without a better conceptualization of agency there are few clues to help scholars adjudicate the connections between institutional logics and human action. To rectify this, and elaborate how actors can respond to institutional complexity, we must give full explanatory weight to agency and conceive the full gamut of human action (Seo \& Creed, 2002; Powell \& Colyvas, 2008) in relation to plural social structures.

These issues resonate with recent commentaries by several leading institutional theorists that have acknowledged the failure to bring together insights from micro- and macro-level studies (Barley, 2008; Hinings \& Tolbert, 2008; Thornton \& Ocasio, 2008; Thornton et al., 2012). For over two decades, amid concerns that the field had become dominated by macro-level studies which emphasized continuity and conformity and reduced actors to unreflexive carriers of institutions, scholars have struggled with the 'paradox of embedded agency'. Yet, more needs to be done before the benefits of a multi-level analysis are revealed. The problem continues to be theoretical and relates to how agency is understood. As Suddaby, Elsbach, Greenwood, Meyer and Zilber have remarked:

A significant element of agency is effectively being attributed to a black box. Actors may well be influential elements of institutional agency, but we must also develop an understanding of how institutional pressures might affect how these actors and their actorhood are socially constructed. (Suddaby et al., 2010, p. 1238)

Addressing this requires further theorization of the concepts of agency, contexts and institutions, and in particular of their inter-relationships.

In this paper we extend recent research on institutional logics by integrating a critical realist (CR) ontology with a relational analytical framework. In terms of ontology, our solution for opening up the 'black box' of agency (Suddaby et al., 2010) is to treat agency and structure as analytically distinct social phenomena (Archer, 1995, 2003). By holding action and structure separate we can ascertain how social structures - including institutional logics - condition action; this is consistent with the central tenet of institutional theory, which is to frame the historical conditioning of 
logics without disembedding actors from the social world. Importantly, this approach provides the conceptual space necessary to explain 'the relations between systems of ideas [logics] and actions that open up spaces for agential intervention' (Mutch, Delbridge \& Ventresca, 2006, p. 613). To achieve this, we integrate CR with Emirbayer and Mische's (1998) concept of 'agentic orientation' and Archer's (2003) 'internal conversation' to explain 'why some actors seek change, when others, placed in the same contexts, are content to accept existing arrangements' (Mutch et al., 2006, p. 616). This combines a position-based and an action-based approach to the study of institutional logics (see Reed, 2012); that is, in depicting the agentic orientations of actors towards logics (by keeping logics and agency analytically separate we can examine the interplay between the two) and exploring their 'internal conversation' to explain the reflexive capacity of actors in relation to those pre-existing logics, we can elaborate the extent to which actors (re)assess their relationships with society. In turn, it is because we come to know institutional logics through social action that we also argue they possess potential and transfactual properties (not deterministic) and this extends the view of structure as 'discursive restraint' in institutional processes (Hardy \& Maguire, 2010).

Our first contribution is to open up the 'black-box' of agency for institutional analysis (Suddaby et al., 2010). While work on institutional logics is based on a multi-level analytical framework (Friedland \& Alford, 1991; Thornton \& Ocasio, 2008; Thornton et al., 2012) this framework does not adequately specify the nature of agency nor how agency and the other levels of analysis connect. Based on the concepts from CR - analytical dualism and a stratified ontology - we clarify the analytical status of both agency and institutional logics and we specify the three domains of analysis needed to evaluate this dialectical relationship.

Our second contribution is a theoretical framework which allows us to identify different actorstructure relationships, freeing us from the narrow interpretation of institutionalization as 'routinized practice'. Bringing together CR with relational sociology (Mutch et al., 2006) allows a framing of the orientations of actors and likely outcomes in terms of institutional maintenance or change.

Our third contribution is to reflect on the explanatory and methodological implications of this framework for exploring how actors inhabit institutions (Binder, 2007; Hallett, 2010; Hallett \& Ventresca, 2006). While an inhabited approach has done much to overcome 'the "people" problem' in institutional accounts (Hallett \& Ventresca, 2006, p. 216), we extend this by reflecting on the implications of CR for an interactionist understanding of institutional complexity and change.

To begin, we outline a case vignette of the design-and-build of luxury yachts (the superyacht field) to illustrate the value of analytical dualism, that is, to treat agency and structure as separate analytical phenomena, in examining conditions of institutional complexity. We then use this synopsis as a mirror to elaborate Friedland and Alford's (1991) logics approach. Next, we explore how the concepts of CR help us to conceive a nested mode of analysis. Then we offer a theoretical framework based on Emirbayer and Mische's 'agentic orientation' and Archer's idea of 'reflexivity' to realize our critical realist approach. We conclude by considering the explanatory and methodological implications of this for studying how actors inhabit institutions.

\section{Exploring Embedded Agency under Conditions of Institutional Complexity}

Recent empirical work in institutional theory has highlighted the complexity of explaining actions and structures in organizational fields, particularly where there are multiple logics in play (Greenwood, Diaz, Li \& Lorente, 2010). Such was the challenge in our own efforts to explain the conduct of different groups of actors within the superyacht construction field. ${ }^{1}$ Specifically, we 
have studied the work of designers and shipyards in the production of these complex luxury products. The actors are variously influenced by logics of aesthetics, engineering and economics. We provide this brief vignette to elaborate the nature of this challenge.

As we explain in what follows, our research shows a contested terrain; the meanings given to the design-and-build process are subject to conflicting interpretations while the various individual project arrangements confirm the existence of different configurations of actor preferences, organizational interests and repertoires of practices used to attain them. We also see long-held tensions among actors being played out in different measure during projects. In our effort to understand the adaptive political actions of players within the field, we became aware that the origins of these institutional sources of action were historical, reflections of a complex and conflictual institutional domain. In turn, the outcome of past actions did not determine action in a straightforward way because actors in equivalent settings often followed different paths of action (some agents saw opportunities where others saw constraints). We believed that these features said something vital about the nature of embedded agency under conditions of institutional complexity because, in talking about 'conditioned action', not only was it incumbent upon us to outline this complexity as the context for action, it was also important to specify what (who and why) was being conditioned, enabled or constrained.

\section{The superyacht field}

Our research has focused on the role of independent designers and their work with shipyards in the construction of superyachts. Until the late 1970s the independent designer did not exist as an actor in the industry because interior and exterior design were conducted in-house by each shipyard's draughtsmen under the supervision of a naval architect. The shipyards' dominance was challenged by an independent designer - Jon Bannenberg - whose intervention (supported by other actors involved in the industry) led to radical shifts in the established power relations (Delbridge \& Edwards, 2008). The advent of a new group of independent designers during the 1970s and 1980s heralded significant changes in the industry's structure and in the meaning ascribed to the superyachts themselves. Where once technical functionality and seaworthiness dominated the concerns of the shipyards, the new independent designers transformed the industry by reframing design around the onboard needs of clients to create luxury floating living spaces. What emerged was a new industry context and a new design approach that aligned with pre-existing professional (engineering) and market logics.

These logics originate from two professional subgroups - naval architecture and industrial design - and from the market since this is a commercial endeavour. The engineering logic is expressed through naval architecture (as a profession) and the practice of translating design intent into manufacturing solutions and delivering a seaworthy vessel. This knowledge and understanding are embodied in the General Arrangement (GA), which defines the volume, length and structural footprint (including bulkheads, electrical and air conditioning ducting) of the vessel. Choices over, for example, the configuration of structures (e.g. helicopter pad, swimming pool, etc.) have to be understood in the context of weight distribution that affects the GA, which is the knowledge domain of naval architects. The design logic confirms those organizing principles associated with aesthetics and the transformative influence of the new independent designers who have become important actors in the field. This logic shapes how the material features of design are conceived, including the superstructure, spatial flow and functional use of the living and working areas and decoration of the vessel.

The engineering and design logics are interdependent because design intent is made manifest using engineering know-how that delivers a stable sailing platform for safe transit and comfortable 
onboard living. In turn, these basic principles are practised in relation to the market logic that confirms the commercial nature of the field. This is manifest in contractual arrangements that specify the exchange relations between the parties involved, and the build budget, which has a temporal dimension based on a completion date. Commissions are therefore understood in terms of mutually negotiated and dependent principles that define the process by which aesthetic choices, quality and performance criteria and profit maximization rules are established. On occasions when, for example, the client is not satisfied then market rules are imposed in the form of penalty payments (for example, for late delivery or poor quality). In turn, when design ideas require novel engineering solutions, then design choices are mediated by technical and financial rules. This relationality is a necessary feature of the process, which unfolds in specific contexts and informs the action options of individuals and organizations.

While these organizing principles enable and constrain the motivations and understandings of the different actors in terms of professional sensibilities, commercial criteria and reputation, we found that they were neither uniformly shared nor enacted. The field is not a homogenous setting, rather the various professional and market logics condition action in specific project contexts and in relation to the experiences and dispositions of different actors. Not all of the designers act innovatively, while not all shipyards exercise complete control over the process because the conditioning effect of these logics is contingent. When we talk of conditioned - constrained or enabled - action we are reminded that constraints need to have something to constrain, and enablers something to enable. The institutional sources of action do not possess an intrinsic capacity to constrain or enable action. Rather, to exert the power to act, institutional logics must 'stand in a relationship such that it obstructs or aids the achievement of some specific agential enterprise' (Archer, 2003, p. 5, original italics). While logics have the power to impede or facilitate the action of different actors, the activation of such powers is contingent upon those agents who conceive of and pursue what might be possible (also see Mutch, 2007).

The importance of treating agency as discrete for analytical purposes in relation to organizational and plural institutional settings became apparent when we looked at the emergence of two different types of project - custom and in-house. Up until the early 1970s, yachts for the wealthy were designed, decorated and built in-house by a small number of European and American shipyards. It was only after the intervention of Jon Bannenberg that custom-built vessels emerged as a legitimate industry offering. Custom projects involve the shipyard with an independent designer in building a one-off yacht for a client, while in-house projects are conducted by the shipyard and their own design team, often building to an established formula. Each project type involves different levels of regulation associated with contractual arrangements and how actors engage in negotiations. For example, projects which rely on in-house shipyard designers for the creative input provide an environment where concerns over economic cost and efficiency - related to the market logic - are prevalent in shaping design. The preference given to standardized features ensures that the relationship between professional (design and engineering) and market logics is resolved using commercial criteria (and bureaucratic organizational structures). However, in custom projects involving independent designers, rather than builds being shaped by risk and cost assessments set by the shipyard, there are usually moves to push the boundaries of the design and budget envelope. Under these conditions, which are characterized by a network arrangement (the independent designer is contracted to the client, not the shipyard), designers exercise their professional interests thereby involving the shipyards, their engineers and the client in potentially complex negotiations informed by varying expectations on aesthetics, functionality and cost.

It is within these complex institutionalized contexts that we identified scope for action as a feature of the social conditions (project and organizational) and agency of designers variously involved 
in these practices. The structural conditioning of the field is not uniform precisely because of the events related to the emergence of independent designers as new actors in the field and because their role (as opposed to that of in-house designers) indicates differences in the positioning of such actors within projects. How actors engage in projects is conditioned by the different project arrangements: independent designers mostly operate through custom builds (a legacy of past battles over who controls design intent) and because they are independent they can anticipate opportunities for innovation. Independent designers also tend to come into the industry through existing design houses, not via shipyards. Their experiences and dispositions are informed by working in these design houses and not the drawing lofts of the shipyards' naval architects. This is not the case with in-house design professionals who, by virtue of the in-house project arrangements and their status as salaried staff in the shipyard, conduct their professional work with the commercial criteria of their shipyard employers mediating design decisions. While their agency is conditioned by the same professional and market logics, these are felt very differently through the in-house bureaucratic processes, authority structures and power relations of the project arrangement. In turn, their dispositions and experiences depart from the independent designer, which means they are strategic in relation to a different reflexive potential and, in this respect, the space for innovative design is more constrained than enabled.

In recent years, several independent designers working with a well-established shipyard have introduced a new way of commissioning, which is to develop limited series of boats that have been ordered by the shipyard rather than a private client. The new project indicates the potential for actors working in particular actor positions to reflect further on their social worlds and to find alternate project arrangements to organize the design-and-build process. On this occasion, a wellresourced shipyard challenged the status quo in terms of the role of independent designers but did so with the co-operation of established and highly reputed designers who had a long-term relationship with the shipyard (based on custom builds). This was an opportunity for the shipyard management to shift the relations by co-opting the independent designers to work for them as the 'client'. Interestingly, this worked both ways; while the new relations enabled managers to take control of the commissioning process, much in the same way as in-house projects have for other shipyards, it suited the independent designers as this guaranteed economic rents. Such changes show how established institutional arrangements are not static and that the motivation for change can be driven by the reflexive deliberations of actors deeply embedded within the field.

Our reading of the different projects within the superyacht field provides a mirror for us to consider how we specify agency, organizations and logics within institutional analyses. To understand the design-and-build processes it is necessary to analyse the way different logics constitute and give meaning to them. These features of the institutional setting are historical in so far as the conditioning influence of the multiple logics is mediated by the different project arrangements that reflect past battles and confirm the distinct actor positions of designers as an outcome of those jurisdictional battles (Abbott, 1988). But as we show, logics do not determine action precisely because the institutional sources of action are a relational feature of the actor position of individuals and their reflexive ability to recognize opportunities. Institutional complexity is understood as a feature of the relationship between logics, actor positions within projects and the agency of the actors reflexively engaging in such activities. This is contingent on the contextual conditions and reflexive abilities of those involved, which can lead to changes in the conditioning effects of those logics.

Our vignette draws attention to a number of issues concerning how the relationships between logics, organizations and agency are conceived and achieved. We suggest that explanations of conditioned action should be based on an inclusive interpretation of agency (Mutch, 2007; Seo \& 
Creed, 2002), which is to treat agency as a distinct analytical category that exists in relation to levels of social structure. Portraying social relationality in this way presents a number of theoretical challenges, which provide us with a point of departure for developing an integrated ontological and analytical framework. Any attempt to explain progressively higher levels of constraint and opportunity in institutional analysis demands that we give attention to the historical development of the field and actor positions; the challenge is to link but not conflate these levels of analysis. While making a distinction between these levels of analysis it is also necessary to show how they inter-relate and, in doing so, recognize the role of actors in deliberately reflecting on the courses of action open to them. These challenges offer the motivation for developing a CR-inspired approach for understanding institutional processes, and adequately recognizing the relational role of actors as they inhabit institutions.

\section{Logics and the Paradox of Embedded Agency}

In the early institutional entrepreneurship literature the challenge was to address the paradox of embedded agency, that is, the problem of accounting for change when the actions of actors are themselves conditioned by the institutions that they wish to change (Holm, 1995). As this work has progressed, there has been a move away from explaining change through exogenous jolts and toward an assessment of endogenous processes. While there were few early attempts to question the internal consistency of institutions (e.g. Leblebici, Salancik, Copay \& King, 1991), more recently institutional scholars have taken strides to review the agency-structure relationship (e.g. Greenwood \& Suddaby, 2006; Greenwood et al., 2011; Leca \& Naccache, 2006; Mutch, 2007; Seo $\&$ Creed, 2002).

The institutional logics perspective, particularly recent work on institutional complexity, has reinvigorated interest in the apparent 'paradox of embedded agency' because society is understood as an inter-institutional system consisting of multiple logics. This has redefined the institutional 'iron cage' to reflect conflict and tension within a plural social system where individual action is understood within a constellation of multiple logics (Goodrick \& Reay, 2011). Although the logics approach holds considerable promise, further work is required to clarify the relationship between agency and structure. For example, many studies of logics tend to examine competing (pairs of) logics and read off the relationship between particular logics with identified actors (Goodrick, 2002; Lounsbury, 2002; Thornton, 2002). While the motivation to examine competing logics often reflects empirical expediency, reading action from structure is an unfortunate by-product that gives the impression of action as 'simply an epiphenomenon of deep structures' (Mutch et al., 2006, p. 615). This is apparent (if unintentional) in the recent work of Jones, Maoret, Massa and Svejenova (2012) who document the creation of the de novo category 'modern architecture' by attributing the actions of clientele with the institutional logics of the state, commerce, religion or family.

This representation is problematic and runs counter to Friedland and Alford's (1991, p. 242) assessment of individual, organizational and institutional levels of analysis which, they argue, should be no more 'real' than the other. Although logics represent the 'axial principles of organization and action' (Thornton, 2004, p. 2) their examination should not relegate agency to a secondorder reflection of those societal orders. This misconstrues the relationship between levels of analysis and what constitutes conditioned action. Certainly, in the superyacht field we did not conclude that designers read off their actions from just the design logic. Rather, designers operated within a plural institutional setting through different project arrangements (actor positions) that placed them within a specific relationship with each of those logics and in turn informed how they might respond, including how they might act to change those contexts. 
Progress towards the incorporation of action into explanations of institutional processes has been made through an emerging body of work that explores the agency required when 'inhabiting institutions' (Binder, 2007; Hallett, 2010; Hallett \& Ventresca, 2006). The focus is on how situated actors enact existing institutions and, in particular, how local social interactions influence the meaning and enactment of institutional logics. Drawing on symbolic interactionism, these scholars theorize interaction to show how actors are actively and collectively engaged in (re-)constructing meaning and thus they 'neither purely rationalize their action nor seamlessly follow institutionalized scripts' (Binder, 2007, p. 549). Research has shown how local conflicts of interest and struggles over meaning can emerge through these interactions (Hallett, 2010) and this allows an important reconnection with the 'old institutionalism' in stressing the significance of intraorganizational politics (Selznick, 1949). Hallett and Ventresca (2006, p. 226) identify three 'signposts' of an inhabited approach: the embeddedness of institutions and interaction in 'obdurate social relations and contexts', the need to embrace meanings as both local and immediate, and broad and public, and a sceptical and inquiring attitude to the assumed operation of organizations.

However, there are limitations to an assessment of logics that is based on the evaluation of interactions. Most notably, there is the danger of conflating action and structure and thereby producing overly voluntarist accounts of the agency of actors. While Hallett and Ventresca (2006, p. 229) expressly state that 'the inhabited institutions approach does not privilege agency over structure', they proceed to acknowledge that 'the imperative to observe interactions has the unintended consequence of promoting methods typically associated with agentive perspectives' (this methodological point is something we will return to later). Much in the same way that studies of competing logics have had the unintended consequence of reading off action from specific logics, the inhabited view runs the risk of obscuring wider structures in its assessment of local interactions. The focus on social interactions obfuscates the pattern of pre-existing logics, while explanations of interaction tend to implicate agency within such processes without adequately theorizing the reflexive capacity of actors. For example, Binder's (2007) study does not explain why and how individuals act nor locate their actions in wider contexts; it remains implicit that agency and structure are interconnected and this produces 'the black box of agency' bemoaned by Suddaby and colleagues (2010). This is a problem that stems from symbolic interactionist underpinnings that emphasize the local and immediate contexts of interaction.

Given the questions prompted by our vignette and these critical reflections, we see value in taking a closer look at CR to examine conditioned action and how it specifies social interaction as a relational feature of complex institutional settings and agency.

\section{The Building Blocks: A Critical Realist Approach to Understanding Embedded Agency}

Critical realism is premised on the conception that

social action occurs subject to relatively enduring economic and social-structural arrangements (e.g., established laws and institutions). These arrangements do not strictly determine action, but they constitute the objective reality within which it takes place, and hence are reflected in the motives and meaning systems of the actors. (Godard, 1993, pp. 290-291)

Social structures serve as 'generative mechanisms' that give rise to action, manifest not in the form of deterministic outcomes but rather as empirical tendencies. Generative mechanisms have emergent properties that reveal their pre-existence and autonomy. Human actors do not create structures 
from nothing; they reproduce or transform them (Archer, 1995; Somers, 1989). This is commensurate with a nested or layered understanding of social reality because, like generative mechanisms, logics are 'analytically removed from the more active struggles over meaning and resources' (Lounsbury, Ventresca \& Hirsch, 2003, p. 72). From CR, the relationship between generative mechanisms and action is conceived using a stratified ontology, which specifies how social structures condition action.

Under this stratified ontology, there are three levels of analysis - the real, actual and empirical. The first is made up of the empirical events that form the basis of commonsense observations, the main focus of positivist studies. At a more abstract level are the structural formations that shape meaning and understanding. Agency is understood in the context of pre-existing logics that have causal powers (the real). However, such complexity does not explain the nature of events, rather, "the real is to be found in the causal mechanisms that produce the event states that we record as the "actual" and it is these causal mechanisms that [social] scientists are concerned to identify and explore' (Mutch et al., 2006, p. 611). How we come to know these mechanisms is not straightforward because - using the language of logics - the societal orders that constitute the inter-societal system may only function within a particular range of constraints, while other logics may confound their impact. The relationship between logics and action is reflected at the level of the 'actual' which is experienced as the culmination 'of the ways in which actors transpose those institutional logics through precise scripts, rules, and norms in specific contexts' (Leca \& Naccache, 2006, p. 632).

Moving from ontological to epistemological considerations, our knowledge of social phenomena is to be found in the relational connection between the observable features of social action and those unobservable structures that shape events. Rather than conflate actors and mechanisms by assuming that agents, ceteris paribus, act rationally, this approach treats causality (and intentionality) as the outcome of the relationality of structure and agency at a given time and place. Hesketh and Fleetwood (2006) thus refer to the 'transfactual' nature of these institutional powers and how their effects must be evaluated in specific contexts and circumstances. Such an approach also rejects any notion that agential intentionality represents an a priori causal force or mechanism. As Somers (1998, pp. 766-767) argues, the social world is not 'composed of agents with essential and unchanging properties that operate independently of the very relationships by which they are constituted'. Rather, understanding of how actors link with their world reveals 'historically shifting sets of agential relationships contingently stabilized in sites'. For example, in the research by Tracey, Phillips and Jarvis (2011) looking at social entrepreneurship, the previous personal experiences of the two students as charity volunteers supporting homeless people shaped their beliefs and informed their subsequent action in establishing an innovative approach to tackling the problem of homelessness. This attention to historical conditioning is significant because the mechanisms of causality are reflected in various contingent 'pathways of agential interaction'. No given path or outcome is defined by this historical conditioning, but an understanding of action is partial without recognition of it.

Such an approach posits that observed empirical associations and the actions of agents can only be understood by reference to these underlying generative mechanisms. However, by separating structure and agency we also recognize that 'the emergent properties of structures and the actual experiences of agents are not synchronized' (Archer, 1995, p. 149). Agents do not experience structures uniformly; rather, they have differing perceptions and depth of knowledge of their contexts, which has implications for how we explain reflexivity and the social construction of actor positions. While agents tend to reproduce pre-existing structures, such processes are never fully stable, absolute or predictable (Hays, 1994; Zucker, 1988); this is an insight that has been developed by 
the inhabited institutions approach (Hallett, 2010). However, what remains to be theorized are the chances and limitations for agency given the origins and nature of those actor positions inhabited by individuals.

In extending the logics approach we adopt analytical dualism because this allows us to explain how and why actors 'can find principles to justify new institutions and challenge existing ones' (Leca \& Naccache, 2006, p. 633). When agency and structure are conflated it is extremely hard to explain the ways actors connect with their socio-historical contexts. This is because structures are "conceptualised as nothing but part of the parcel that is "social practices"" (Archer, 1995, p. 105, original italics). From a CR perspective, social structures reveal 'a prior distribution of interests vested in social positions which antedate their holders' (Archer, 1995: 130). For example, the options of the independent and in-house designers revealed distinct 'institutional constellations' (Goodrick \& Reay, 2011) which, through the actor positions of designers within the different project arrangements, shaped the opportunities and motivations for transformation. This means that 'interests are built into positions by the relationship of that position to others' (Archer, 1995, p. 130, original italics). For analytical purposes, to explain these actor positions it is crucial to confirm the status of different logics that reveal the fault lines along which agency can be explored. This draws our attention to the 'actual' domain of analysis, which is when conditioned action can be observed. Explanations of the here-and-now of inhabited interaction would, as a result, be considered through discrete analytical moments: structural conditioning, social interaction and structural elaboration (outcomes) (Archer, 1995, p. 160).

When we refer to structural conditioning we are not only concerned with logics in their most abstract representation, we are also interested in their causal potential. We agree with Archer (2003, p. 7, original italics) who states: 'it is necessary to distinguish between the existence of structural properties and the existence of their causal powers'. While logics have the power to facilitate or restrain the actions of agents who are differentially placed in a social setting, their impact is contingent on the actors who variously conceive of and pursue their particular projects. Instead of reading off action from logics, the challenge is to assess the configuration of logics within a meaningful context, giving due attention to both the organizational setting and agentic properties of those involved. To explain how logics condition action it is not enough to characterize the social orders within which actors operate or the interactions in which actors engage; it is necessary to specify the vertical integration of these features (Archer, 2003; Emirbayer \& Mische, 1998). Explaining conditioned action in this way requires an additional conceptual step, which is to elaborate such conditioning in relation to human actors.

\section{From Critical Realist Building Blocks to a Theoretical Framework: An Integrated Approach}

While our project is not the first to draw insights from CR (Leca \& Naccache, 2006; Mutch, 2007) we elaborate this line of theoretical work through an expansion of CR to explore agency, institutional complexity and change. Scholars have considered how CR can help explain institutional entrepreneurship, but this research has stopped short of exploiting the potential of CR to develop a refined theorization of institutional reproduction and transformation. By integrating a CR ontology with a sensitizing framework that helps to explain the reflexive deliberations of actors, we see the potential to extend work on CR and institutional entrepreneurship to address the wider challenge of institutional complexity. We see this as an opportunity to refine understanding of how actors inhabit institutions. 
It is because CR is not itself a theory that we need to borrow commensurate concepts to develop a theoretical framework to explore 'conditioned action'. Our approach resonates with DiMaggio's (1997) proposal for the study of culture, where lessons from psychology and the sociology of culture are brought together. While we are not advocating the fusing of psychology and sociology, we do recommend bringing together Emirbayer and Mische's (1998, p. 998) treatment of agency with Archer's (2003) concept of the 'internal conversation'. This framework depicts the different agentic orientations towards logics and the 'internal conversation' outlines different forms of reflexivity in the context of existing logics; this helps to explain the extent to which actors are able to assess their relationships with their social worlds.

This re-invigorates the idea of agency because the focus on reflexivity means that actors are thought to actively 'engage' with logics: 'agents have to respond to these influences; which being conditional rather than deterministic, are subject to reflexive deliberation over the nature of the response' (Archer, 2003, p. 8). And, given the mutability and multiplicity of logics, the nature and outcomes of such reflexivity are neither fixed nor given. This also draws attention to a further advantage of this framework, which is to signal the importance and origins of contest within institutional settings and, in particular, how actors confront and overcome different and conflicting interests.

Developments in relational sociology reveal a concern with how we might best situate organizational practice (Mutch et al., 2006). For Emirbayer (1997), the key is to theorize organizations as situated 'processes' rather than entities, thereby drawing our attention to the importance and role of social context. Following a nested mode of analysis, the implication of this approach is to recognize that the units of that analysis (actors and structures) are dynamic with ongoing processes of negotiation and accomplishment. Here we see value in the definition of agency provided by Emirbayer and Mische:

The temporally constructed engagement by actors of different structural environments - the temporal relational contexts of action - which, through the interplay of habit, imagination, and judgement, both reproduces and transforms those structures in interactive response to the problems posed by changing historical situations. (Emirbayer \& Mische, 1998, p. 970)

In recognizing that institutional reproduction is not fixed nor certain, this approach points to the possibility of both stasis and change in the context of changing historical situations. Such variability is represented with reference to three agentic orientations: an iterational element which gives 'stability and order to social universes ... helping to sustain identities, interactions and institutions over time' (Emirbayer \& Mische, 1998, p. 998); a projective element or the 'imaginative generation by actors of possible future trajectories of action, in which received structures of thought and action may be creatively reconfigured in relation to actors' hopes, fears and desires for the future' (Ibid, p. 998); and finally, a practical-evaluative element which entails 'the capacity of actors to make practical and normative judgments among alternative trajectories of action, in response to the emerging demands, dilemmas, and ambiguities of presently evolving situations' (Emirbayer \& Mische, 1998, p. 971). Here we see the means to frame variation in the way actors conduct themselves as institutional domains unfold. How actors engage with their immediate environment often reveals the ebb and flow of concurrent logics that may or may not come into contact or conflict at specific moments (Lawrence, Wynn \& Jennings, 2001).

Given the potential for different agentic orientations, Archer's (2003) typology of the 'internal conversation' presents a way to explain how actors react to such conditioning. This extends Emirbayer and Mische's (1998) work because Archer (2003) allows us to characterize how actors 
variously engage with different social structures. While Emirbayer and Mische (1998) show that agency is a feature of social reality that represents more than just routinized action, Archer (2003) identifies the specific properties and powers agents possess that are distinct from those pertaining to social forms. Whereas Emirbayer and Mische (1998) note the many ways in which structure impinges upon actors, Archer (2003) specifies the range for reflexive deliberation available to actors engaged in these different relationships. Reflexivity is the mechanism through which choices are made: 'agents have to diagnose their situations, they have to identify their own interests and they must design projects they deem appropriate to attaining their ends' (Archer, 2003, p. 9).

According to Archer (2003), human actors are reflexive in different ways. In her analysis Archer refers to communicative reflexives as those who complete their internal conversation intersubjectively or in the context of others. The personal projects of communicative reflexives reflect this 'contextual continuity', which shapes what they deem as important. This type of actor tends to undertake deliberations with reference to those around them - their opinions matter - precisely because they tend to share common concerns, interests and contexts. This is close to the ideas posited by Hedstrom and Swedberg (1998, p. 13) who argue that the actions of individuals are orientated around the behaviour of others. Thus, communicative reflexives are embedded in existing arrangements in such a way that scope for change is limited (i.e. unwanted or unrecognized). Reflecting on our vignette, we see the potential of framing the actions of in-house designers in the same way. Innovative design is measured against the off-the-shelf design solutions that resonate with the risk calculations of the naval architects and cost projections of the shipyard accountants. While innovation remains an option (because the designers operate within a complex institutional setting), in-house projects tend to 'filter' how the institutional sources of action are experienced, which in this case reveals embedded power relations within the shipyards that create more constraints than enablements. We suggest that their internal conversation will be coloured in certain ways because how they weigh up their options (in conversation with others employed in the shipyard) is likely to confirm pre-existing relations and arrangements that create limitations in what they imagine is possible. In such a context, the nature of the internal conversation and the scope for reflexive deliberation discloses progressively higher levels of constraint based on the desire to maintain continuity rather than seeking opportunity for change.

In turn, there are those actors whom Archer (2003) terms autonomous reflexives. These actors conduct their internal conversation 'at distance' from existing arrangements, which can lead to contestation with incumbents as these actors seek to pursue their own projects despite the social structures that surround them. Such personal projects differ from those of the communicative reflexive because they reflect 'contextual discontinuity', which means the biography of the autonomous reflexive is more disrupted and as such they are not defined by stable relations or contexts. Such actors establish and reflect on their personal projects in the absence of external exchanges that might reveal embedded interests. This means that they engage in a process of self-monitoring, assessing how their preferred projects might be made possible despite the context in which they find themselves. This position is close to the idea of institutional entrepreneurs and their efforts to instigate change (Mutch, 2007). Such reflexive deliberations seemingly resemble those of the independent designers because they operate in the knowledge that their design choices are not constrained in the same way as those of in-house designers. Within the custom build setting, independent designers experience contextual discontinuity because projects are unique collaborations with a wide variety of actors in diverse social settings. Not only does this mean that they have far more scope to negotiate design intent but, unlike in-house designers, these experiences also help to ensure that they can see how they might 'make' opportunities for innovative design. This is not to suggest that all independent designers are equally innovative or unconstrained, far from it, but 
design intent reflects the actor positions of designers in relation to their own experiences. This confirms the importance of individual agency. It is not just the conditioning of social settings that explains action but both the individual propensity and strategic judgement for taking a particular action path which needs explaining. This emphasizes how contextual conditions (multiple logics) and the actions of individuals within given contexts influence their reflective capacity, which is also a feature of their past experiences established over time and the shaping effect of institutional arrangements (Delbridge \& Edwards, 2008; Leca \& Naccache, 2006; Tracey et al., 2010). Such complexity also helps explain how logics can coexist over sustained periods of time without any single logic prevailing (Goodrick \& Reay, 2011; Kraatz \& Block, 2008; Purdy \& Gray, 2009).

Meta reflexives are those who not only monitor personal projects but also review the reflective process itself. While this internal process does not necessarily invoke change it does reveal that actors can be aware and concerned about the status quo, and therefore sometimes remove themselves from social situations which would not enable them to act in line with their own personal interests. As with autonomous reflexives, these actors have experienced contextual discontinuity and may actively embark on political processes when confronted with conflicting institutional demands (Pache \& Santos, 2010). As our brief discussion of the superyacht field suggests, some independent designers in certain positions reflect differently from others in a similar situation on how they engage in social relations. Indeed, there are occasions when independent designers have refused to work with clients because they feel that they have to make too many creative concessions. Unprepared to make such compromises in the pursuit of their ideals, they have withdrawn from the process, looking for a new design opportunity with an alternative client. This desire to fulfil their ideals draws attention to the way different actors make sense of their immediate contexts and the constellation of logics shaping their action (Goodrick \& Reay, 2011). However, further theorizing is needed because, while scholars have reported 'segmenting' as the recasting of professional work between different logics - 'logics are comprised of decomposable component parts that can be recombined in different ways' (Goodrick \& Reay, 2011, pp. 379-380) - little has been said about the role of agents in this segmenting process or how actors read this process as an opportunity or barrier to their work.

The final category is the fractured reflexive. Such actors are the victims of society who are unable, for whatever reason, to engage in an internal conversation. These actors are the closest to being 'social dopes'; it is because of their involuntary positioning in society that they are unable to change their situation.

This discussion permits us to anticipate the potential outcomes of different couplings of agentic orientation and categories of reflexivity (Table 1). This is not meant to be exhaustive but allows reflection on the forms of relationality that can potentially exist. In doing so, we can begin to reassess the paradox of embedded agency and how actors inhabit institutions because different patterns of orientation-reflexivity suggest actor-contexts combinations that are more or less likely to result in stability or change.

The connection between actors and logics is expressed in the way logics and contexts shape action at any given time. On those occasions when dominant logics (deeply embedded over large tracts of time) exist then fields will be characterized by narrowly defined and relatively uncontested principles. At such moments, actors who engage in their internal conversation intersubjectively will be disposed toward pre-existing organizing principles (iterational orientation), which will be manifest in relatively stable social arrangements. These arrangements will be taken for granted and the scope for disruptive action will be limited. The internal conversation of incumbents is likely to reveal this taken-for-grantedness. It can also indicate the relative isolation of some individuals who - as a feature of their actor positioning - are more constrained than enabled. 
Table I. The agency-structure relationship: structural transformation and reproduction.

\begin{tabular}{lll}
\hline Agentic orientation & $\begin{array}{l}\text { Action orientation: internal } \\
\text { conversation }\end{array}$ & $\begin{array}{l}\text { Potential outcomes: } \\
\text { transformation/reproduction }\end{array}$ \\
\hline Past & $\begin{array}{l}\text { Iterational: communicative/ } \\
\text { fractured reflexive } \\
\text { Practical-evaluative: meta/ } \\
\text { autonomous reflexive } \\
\text { Projective: autonomous reflexive }\end{array}$ & Taken-for-granted continuity \\
Future & $\begin{array}{l}\text { Negotiated continuity and/ } \\
\text { or change } \\
\text { Change }\end{array}$ \\
\hline
\end{tabular}

However, consistent with the CR approach, the relationship between structure and action is not fixed precisely because actors have the capacity to reflect on their social circumstances (Archer, 2003). At times, actors may begin to question existing arrangements (Greenwood \& Suddaby, 2006; Seo \& Creed, 2002). This does not necessarily mean that they will act on these reflections but there remains the chance that, as actors come into contact with multiple logics (knowingly or otherwise), the potential for agency shifts (Emirbayer \& Mische, 1998). As we indicate in the case vignette, multiple logics coexist in different measure through a variety of project types. The logics do not act on people in a deterministic fashion but they are felt differently through those distinct arrangements (Goodrick \& Reay, 2011) and because actors are reflexive in different ways, which says something about their own 'institutional biography' (Suddaby, Viale \& Gendron, 2012).

Recognizing the institutional sources of action confirms the interplay of these rules of the game; but these multiple rules play out in different ways and it is in the context of these interactions that we can see the dynamics between actors in co-operation and conflict when new arrangements may emerge (e.g. series boats). Constraints become enablers as the reflexive deliberations of actors lead to change or, as in our case of custom build projects, they indicate the need to negotiate among antagonistic meanings (Delbridge \& Edwards, 2008; Fligstein, 1997; Marquis \& Lounsbury, 2007). As argued above, this reveals the reflexive deliberations of those individuals involved as separate but relational to the institutional setting and the social arrangements that constitute emerging events.

This sensitizing framework not only benefits from the complementary configuration of those concepts taken from Archer (2003) and Emirbayer and Mische (1998) but it also relies on the concepts of CR. The explanatory utility of our approach is realized in the search for multiple causal mechanisms (logics) and the emergence of phenomena over time (organizational arrangements and actor positions) that elaborate the origins and reflexive capacity of actors. We offer theory developments around the work of Emirbayer and Mische (1998) not simply because we integrate the concept of reflexivity (Archer 2003) to explain the role of actors within conditioned action but because we delimit how we access structures in relation to action. This historical and socio-economically informed explanation has the potential for delivering causal explanations of constraints and enablements that elaborate how actors might inhabit institutions.

\section{A Critical Realism-Inspired Approach for Explaining how Actors Inhabit Institutions}

The ideas behind $\mathrm{CR}$ allow us to develop a more robust conceptualization of the relationships across levels (society, organization and actor) and between logics, contexts and action. These concepts also allow us to reflect on the way actors inhabit institutions and the methodological steps that need to be taken to put our theoretical framework into use. The key advance offered by our 
CR-inspired approach is to give due attention to the reflexive capacities of the agent which recognizes the importance of past experiences in shaping whether actors assess situational circumstances as enabling or constraining. Giving closer attention to the internal conversation of actors and the influence of their personal biographies ensures that we account for the way past institutional experiences influence whether actors engage with their world to change or maintain it (which in turn shapes their monitoring of those personal projects). Yet, this condition is not fixed because these modes of reflexivity are formed as an outcome of past experiences and the contextual circumstances within which actors find themselves at any given moment. This means that actors inhabit institutions in relation not simply to the past according to situational circumstances (i.e. project types as described in our case vignette), but also in terms of the personal histories of those involved in such processes. By keeping structure and agency separate it is possible to reflect on how these distinct analytical categories come together through social interaction. Our view of the individual is framed by the mode of reflexivity in relation to different agentic orientations that are a feature of specific organizational and social settings. Although social interactions reveal the relative deliberations of human actors, such moments are not explained by the interactions themselves. Rather, social interactions offer a mechanism to assess the relational intersection of structural and agentic properties at a given time.

Our proposed framework resonates with the work of Suddaby and colleagues (2012) who also seek to rectify the marginalization of individuals within institutional studies. There is resonance because they draw attention to the importance of the historical development of actors as evidenced through their exposure to various institutional settings. This, they argue, allows actors to develop a distinct 'institutional biography'. We would add that the mode of reflexivity is dependent on whether this personal history was formed as part of contextual continuity or discontinuity (Archer, 2003). Reflexivity is not just about accumulated experiences. The mode of reflexivity indicates how different actors view their social world in terms of specific personal projects which are, in turn, (re-)formed over time.

Wilcox's (2012) work on moral agency in HRM practice is a good empirical illustration of the basics of our argument. In this work, Wilcox indicates the importance of different personal characteristics for enabling a tight group of HR managers to navigate the conflicting meanings associated with a downsizing process. While Wilcox does not explicitly discuss the past experiences of the HR managers in terms of institutional biographies, she draws attention to the managers' professional and religious affiliations and deep concerns when explaining the origins of their efforts to create alternate meanings to offset the worst aspects of the cost-cutting exercise. It is the exposure to different institutional principles that enables the managers to conceive of different outcomes. In turn, not only does this work allude to reflexivity for navigating social settings, defined by institutional complexity, it also points to the role of relational spaces for allowing the HR managers to think critically. Their closed meetings were occasions when like-minded managers could confide in one another and find different ways to mitigate the downsizing policy.

Such an analysis presents a nested representation of individuals, organizational settings and complex institutional domains, which formed the basis for explaining interactions within this politicized and contested corporate setting. The explanatory emphasis incorporates not simply the social interactions of the managers but also the basis of their reading of the situation as a feature of their personal histories and the corporate process of downsizing.

\section{Methodological implications}

Insights into how to develop this kind of multi-level analysis can be found in the "extended case method' elaborated by Burawoy (2009). Burawoy argues that research topics should be assessed at 
the micro level and then extended to progressively higher levels of analysis depending on the subject matter. The challenge is how we might locate social interactions in their broader socioeconomic context. To do this, he contends that researchers must address two questions: First, they must decide which of these levels of analysis is the focus of the research. Second, they must conceive of how these levels are to be adequately connected.

To return to our initial vignette, at the centre of our study were the actions and decision-making processes of those actors involved in the superyacht design-and-build process. Our empirical task was to explain how design intent was translated into material artefacts, given the unique and innovative nature of the industry. Moving up from the micro level, it became apparent that to understand the scope for design intent it would be necessary to reflect on the project arrangements which shaped the actions of actors. These micro-level actions and meso-level units of analysis provided the building blocks to explore conditioned action in relation to pre-existing professional and market logics and the organizations and individuals involved. The key explanatory task was in discovering how this relationality 'played out' through the project types. As Archer (2003, p. 8, original italics) remarks, 'Whether or not their [i.e. logics] causal power is to constrain or to enable is realised, and for whom they constitute constraints or enablements, depends upon the nature of the relationship between them and agential projects'.

These insights elaborate a CR-inspired approach for examining the way actors inhabit institutions. The focus on social interactions is important because at this level of analysis (the empirical) we are able to access local project-level negotiations. In assessing different build projects involving in-house and custom arrangements it became possible to reflect on differences in the scope for action within project types. The focus on actor positions was significant not only because these framed the context of conflict and contestation within projects but also because they 'signalled' the outcome of past battles. This drew our attention to the importance of building the necessary historical analysis of the organizational forms that shaped this process. Combining 'historical' and 'realtime' analysis creates the empirical architecture to allow the researcher to 'toggle' back-and-forth between accessing the conditioning effects of past events with subsequent and unpredictable struggles within specific project arrangements. For example, when we considered the emergence of the series builds we were alerted to the empirical importance of social interactions - the focus of the inhabited approach - to explain change. However, we were also aware that such changes should be explained by holding both structure and agency apart (explaining the relation between the two) because the enabling and constraining impact of the institutional sources of action varied, depending on the projects embarked upon by the different actors.

Such critical reflection across projects - in-house, custom and series - helps to overcome the criticism of existing inhabited approaches that deliver ahistorical or overly agentic accounts of interaction. This also draws attention to the importance of a stratified ontology because the object of the analysis is to ascertain 'the actual' manifestation of the generative mechanisms that have potential causal powers (Archer, 2003). As observed in our study, although the market and professional logics are integral to explaining action, they are constraining and enabling in different measure depending on the project and the organizations/designers engaged in the unfolding context of interactions. The explanation of such dynamics depends on an integrated theoretical framework. Thus, explanations of agency are captured as a relational feature of the agentic orientation of actors within the context of those meso-structures that influence the reflexive deliberations of actors.

This approach changes the emphasis of existing inhabited studies from a single analytical moment - social interaction - to one that incorporates three distinct moments. Distinguishing between these three analytical moments of (i) the structural conditioning of institutional 
logics; (ii) the interplay of such logics at the level of the actual; and (iii) the empirical outcome of such interplay, it is possible to interpret the past against the present, freeing the inhabited approach from the pitfalls of conflationism, which means not losing sight of either the origins or the agentic complexities of institutional change and maintenance. Put another way, CR combines an action-based approach with a position-based approach such that the complex interaction between institutionalized power structures and emergent power dynamics may be explored (Reed, 2012). Recognition of the pre-existence of social structures is important for this reason too. The methodological implications of this approach mean that, for analytical moment one, we specify the structural conditioning of action as a prelude to detailed analysis of social interactions. This requires data that allow an historical grounding of the evidence gathered in the immediate period. As with our vignette, it was essential to understand the antecedents of project activities before it was possible to explain the conflict and negotiation that was apparent in different measure within projects. Understanding the complex and negotiated nature of these project arrangements required detailed and rich data of the design-and-build process. Analytical moment two relies on intensive periods of study in the field based on a range of methods including interviews and observations. The last analytical moment requires us to present a longitudinal appraisal of actions and outcomes in order to explain whether such social interactions have led to transformation or reproduction. Such developments build on and extend an inhabited institutions approach because this situating of the focal points of empirical assessment in their wider social and historical contexts ensures that robust theoretical insights are developed.

\section{Conclusions}

In this paper we offer a series of refinements and extensions to new institutionalist theorizing that are founded on critical realist social theory (Archer, 1995; Somers, 1998). Interest in CR has been growing across management and organization studies (Al-Amoudi \& Willmott, 2011) and its adoption here provides analytical and conceptual clarity in order to extend the capability of current theorizing to deal with multilevel analyses (avoiding bifurcation around a micro-/macro- division), strengthening the conception of agency in understanding how actors inhabit institutions and elaborating the importance of actors' agentic orientations and personal histories. In particular, we assess the historical contexts of local actions and interactions and the exact nature of reflexive deliberation, which is a constituent feature of conditioned action.

This is an important development of existing approaches because, while there is general agreement that the relationship between individuals and institutional logics is contingent, reflecting either opportunities or constraints (Thornton et al., 2012, p. 76), more needs to be said of the mechanisms through which conditioned action is theorized. For instance, although it is acknowledged that 'institutional contradictions provide individuals and organizations with opportunities for agency and institutional change by exploiting these contradictions' (Thornton et al., 2012, p. 77), it is also accepted that 'a full understanding of the role of social actors in shaping and being shaped by institutions requires a more developed theory of human behaviour' (p. 77). While progress has been made with Thornton's (2004) work on assessing the way logics shape the formation of cognitive schema, greater insight into how actors reflect upon meanings within complex institutional settings is required. To achieve this, we have mapped out the inter-relationships of historically produced social structural contexts and actors' past histories, orientations and modes of reflexivity. Our aim has been to help explain this process by revealing why in some situational circumstances actors sometimes see 
opportunities for change, while other actors in the same position are unable (unaware and unwilling) to challenge practices (Mutch et al., 2006).

Our incorporation of Archer's (2003) work on reflexivity and Emirbayer and Mische's (1998) work on agentic orientation has allowed us to respond to the call for a 'situated, embedded, boundedly intentional model of human behaviour' (Thornton et al., 2012, p. 80). Indeed, our work allows us to develop the 'inhabited' approach by unpacking how actors reflect on this process; that is, analytical dualism allows us to reveal the historical, local and agentic basis of conditioned action (Archer, 2003). This offers the means to explain the basis of social interaction when actors inhabit institutions (Hallett \& Ventresca, 2006, p. 216).

Our case vignette provided a mirror, prompting important questions about the nature of social enquiry and how we might incorporate explanations of institutional sources of action without giving undue emphasis to the structural elements and thereby (inadvertently) relegating the other levels of analysis - locales and actors - to second-order themes in the analytical process. In addressing these questions, this paper makes three main contributions to current theorizing with particular emphasis on elaborating institutional complexity (Friedland \& Alford, 1991). Our first contribution is to address agency and structure while avoiding the pitfalls of conflationism, determinism and voluntarism. Here we reassess the idea of embedded agency and institutional change as paradoxical. We utilize the insights from CR's analytical dualism and stratified ontology to produce a conceptualization that recognizes, and provides the basis for evaluation of, the connections between agency and structure across different levels of aggregation. This conceptual framing shows how logics deriving from these sectors of society come to shape meaning and practices at organizational levels which both constrain and enable action by actors. This approach allows us to open up the 'black box' (Suddaby et al., 2010) and acknowledge how structural conditioning shapes the agency and personal processes of reflexivity possible to individuals within their relevant historical and organizational contexts.

Second, we integrate a CR ontology with a theoretical framework that links agency and personal processes of reflexivity to guide research and future theorizing of the non-deterministic nature of social structures and the agency of actors. The combination of CR with relational sociology thus provides a framing to allow both the assessment of the orientations of actors and the likely outcomes in terms of institutional maintenance or transformation. In particular, this highlights the inter-relational aspects of institutional complexes of multiple logics, contexts and actors. A theoretical approach underpinned by CR anticipates and evaluates the emergent properties of structures (including logics) over time and offers improved understanding of the outcomes of multiple logics in situ. Social structures have a transfactual potential to exercise influence on (but not determine) action. They thus operate as 'generative mechanisms' to shape, constrain and enable action. Outcomes are subject to empirical evaluation and provisional causal explanation.

Third, we reflect on the methodological implications of researching institutional complexity using our proposed integrated approach. This provides the basis for extending an inhabited approach and looks to combine a focus on social interactions with an historical sensitivity. An extended case method uncovers not simply the deeply embedded and conditioning effects of logics but also the shaping (and historical) role of social arrangements and the agentic projects of actors. As indicated with our vignette of the superyacht industry, such historical analysis helps to explain the scope for reflexive action and highlights how local contexts condition the space for alternate meanings and practices to emerge. It is our hope that future empirical research can both benefit from the application of this framework and offer further refinement of it, thereby advancing our understanding of the complex interplays between logics, contexts and individuals. 


\section{Acknowledgements}

The authors would like to thank Royston Greenwood, Roy Suddaby and Mike Reed for their guidance and encouragement in developing this paper. We would also like to thank David Courpasson and the reviewers who pushed us to develop our ideas further.

\section{Funding}

Funding for the superyacht project came from a British Academy Small Grant Award SG 36137 (2003-04) and from the UK's Economic and Social Research Council/Engineering and Physical Sciences Research Council (ESRC/EPSRC) Advanced Institute of Management Research [Grant ESRC RES-331-25- 0014].

\section{Note}

1. Superyachts are oceangoing vessels of at least 25 metres in length. They can be either motor or sailing yachts and are usually built for individual clients for personal use. Such vessels are increasingly being built to industry safety standards that allow for chartering.

\section{References}

Abbott, A. (1988). The system of professions: An essay on the division of expert labor. Chicago: University of Chicago Press.

Al-Amoudi, I., \& Willmott, H. (2011). Where constructionism and critical realism converge: Interrogating the domain of epistemological relativism. Organization Studies, 32, 27-46.

Archer, M. (1995). Realist social theory: The morphogenetic approach. Cambridge, UK: Cambridge University Press.

Archer, M. (2003). Structure, agency and the internal conversation. Cambridge, UK: Cambridge University Press.

Barley, S. R. (2008). Coalface institutionalism. In R. Greenwood, C. Oliver, K. Sahlin \& R. Suddaby (Eds.), The Sage handbook of organizational institutionalism (pp.491-518). London: SAGE Publications.

Binder, A. (2007). For love and money: Organizations' creative response to multiple environmental logics. Theory and Society, 36, 547-571.

Burawoy, M. (2009). The extended case method: Four countries, four decades, four great transformations, and one theoretical tradition. Berkeley: University of California Press.

Delbridge, R., \& Edwards, T. (2008). Challenging conventions: Roles and processes during non-isomorphic institutional change. Human Relations, 61, 299-325.

DiMaggio, P. J. (1997). Culture and cognition. Annual Review of Sociology, 23, 263-287.

Dunn, M. B., \& Jones, C. (2010). Institutional logics and institutional pluralism: The contestation of care and science logics in medical education 1967-2005. Administrative Science Quarterly, 55, 114-149.

Emirbayer, M. (1997). Manifesto for a relational sociology. American Journal of Sociology, 103, 281-317.

Emirbayer, M., \& Mische, A. (1998). What is agency? American Journal of Sociology, 104, 962-1023.

Fligstein, N. (1997). Social skill and institutional theory. American Behavioral Scientist, 40, 397-405.

Friedland, R., \& Alford, R. R. (1991). Bringing society back in: Symbols, practices, and institutional contradictions. In W. W. Powell and P. J. DiMaggio (Eds.), The new institutionalism in organizational analysis (pp. 311-336). Chicago, IL: University of Chicago Press.

Godard, J. (1993). Theory and method in industrial relations: Modernist and postmodernist alternatives. In R. Adams \& N. Meltz (Eds.), Industrial relations theory: Its nature, scope and pedagogy (pp. 283-306). Mefuchen, NJ: IMRL/Rutgers University Press.

Goodrick, E. (2002). From management as a vocation to management as scientific activity: An institutional account of a paradigm shift. Journal of Management, 28, 649-668.

Goodrick, E., \& Reay, T. (2011). Constellations of institutional logics: Changes in the professional work of pharmacists. Work and Occupations, 38, 372-416. 
Greenwood, R., \& Suddaby, R. (2006). Institutional entrepreneurship in mature fields: The big five accounting firms. Academy of Management Journal, 49, 27-48.

Greenwood, R., Diaz, A. M., Li, S. X., \& Lorente, J. C. (2010). The multiplicity of institutional logics and the heterogeneity of organizational responses. Organization Science, 21, 521-539.

Greenwood, R., Raynard, M., Kodeih, F., Micelotta, E. R., \& Lounsbury, M. (2011). Institutional complexity and organizational responses. Academy of Management Annals, 5, 317-371.

Hallett, T. (2010). The myth incarnate: Recoupling processes, turmoil and inhabited institutions in an urban elementary school. American Sociological Review, 75, 52-74.

Hallett, T., \& Ventresca, M. J. (2006). Inhabited institutions: Social interactions and organizational forms in Gouldner's Patterns of Industrial Bureaucracy. Theory and Society, 35, 213-236.

Hardy, C., \& Maguire, S. (2010). Discourse, field-configuring events and changes in organizations and institutional fields: Narratives of DDT and the Stockholm convention, Academy of Management Journal, 53, $1365-1392$.

Hays, S. (1994). Structure and agency and the sticky problem of culture. Sociological Theory, 12, 57-72.

Hedstrom, P., \& Swedberg, R. (1998). Social mechanisms: An introductory essay. In P. Hedstrom \& R. Swedberg (Eds.), Social mechanisms: An analytical approach to social theory (pp. 1-32). Cambridge, UK: Cambridge University Press.

Hesketh, A., \& Fleetwood, S. (2006). Beyond measuring the human resources management-organizational performance link: Applying critical realist meta-theory. Organization, 13, 677-699.

Hinings, R., \& Tolbert, P. (2008). Organizational institutionalism and sociology: A reflection. In R. Greenwood, C. Oliver, K. Sahlin \& R. Suddaby (Eds.), The Sage handbook of organizational institutionalism (pp. 473-490). London: SAGE Publications.

Holm, P. (1995). The dynamics of institutionalization: Transformation processes in Norwegian fisheries. Administrative Science Quarterly, 40, 398-422.

Jones, C., Maoret, M., Massa, F., \& Svejenova, S. (2012). Rebels with a cause: Formation, contestation and expansion of the de novo category 'modern architecture', 1879-1975. Organization Science, 23, $1523-1545$.

Kraatz, M. S., \& Block, E. S. (2008). Organizational implications of institutional pluralism. In R. Greenwood, C. Oliver, K. Sahlin \& R. Suddaby (Eds.), The Sage handbook of organizational institutionalism (pp. 243-275). London: SAGE Publicaitons.

Lawrence, T. B., Winn, I. M., \& Jennings, P. D. (2001). The temporal dynamics of institutionalization. Academy of Management Review, 26, 624-626.

Leblebici, H., Salancik, G., Copay, A., \& King, T. (1991). Institutional change and the transformation of interorganizational fields: An organizational history of the US radio broadcasting industry. Administrative Science Quarterly, 36, 333-363.

Leca, B., \& Naccache, P. (2006). A critical realist approach to institutional entrepreneurship. Organization, $13,627-651$.

Lounsbury, M. (2002). Institutional transformation and status mobility: The professionalization of the field of finance. Academy of Management Journal, 45, 255-266.

Lounsbury, M., Ventresca, M., \& Hirsch, P. (2003). Social movements, field frames and industry emergence: A cultural-political perspective on US recycling. Socio-Economic Review, 1, 71-104.

Marquis, C., \& Lounsbury, M. (2007). Vive la resistance: Competing logics and the consolidation of US community banking. Academy of Management Journal, 50, 799-820.

Mutch, A. (2007). Reflexivity and the institutional entrepreneur: A historical exploration. Organization Studies, 28, 1123-1140.

Mutch, A., Delbridge, R., \& Ventresca, M. (2006). Situating organizational action: The relational sociology of organizations. Organization, 13, 607-626.

Pache, A-S., \& Santos, F. (2010). When worlds collide: The internal dynamics of organizational responses to conflicting institutional demands. Academy of Management Review, 16, 145-179.

Powell, W. W., \& Colyvas, J. A. (2008). Microfoundations of institutional theory. In R. Greenwood, C. Oliver, K. Sahlin-Andersson \& R. Suddaby (Eds.), The Sage handbook of organizational institutionalism (pp. 276-298). London: SAGE Publications. 
Purdy, J. M., \& Gray, B. (2009). Conflicting logics, mechanisms of diffusion, and multilevel dynamics in emerging fields. Academy of Management Journal, 52, 355-380.

Reed, M. I. (2012). Masters of the universe: Power and elites in organizational studies. Organization Studies, $33,203-222$.

Selznick, P. (1949). TVA and the grass roots: A study in the sociology of formal organization. Berkeley: University of California Press.

Seo, M-G., \& Creed, D. W. E. (2002). Institutional contradictions, praxis, and institutional change: A dialectical perspective. Academy of Management Review, 27, 222-247.

Somers, M. R. (1998). We're no angels: Realism, rational choice, and rationality in social science. American Journal of Sociology, 104, 722-784.

Suddaby, R., Elsbach, K. D., Greenwood, R., Meyer, J. W., \& Zilber, T. B. (2010). Organizations and their institutional environments: Bringing meaning, values and culture back in: Introduction to the special research forum. Academy of Management Journal, 53, 1234-1240.

Suddaby, R., Viale, T., \& Gendron, Y. (2012). Institutional reflexivity: The role of the individual in institutional work. Paper presented at Meiji University, Japan, October.

Thornton, P. H. (2002). The rise of the corporation in a craft industry: Conflict and conformity in institutional logics. Academy of Management Journal, 45, 81-101.

Thornton, P. H. (2004). Markets from culture: Institutional logics and organizational decisions in higher education publishing. Stanford, CA: Stanford University Press.

Thornton, P. H., \& Ocasio, W. (2008). Institutional logics. In R. Greenwood, C. Oliver, K. Sahlin \& R. Suddaby (Eds.), The Sage handbook of organizational institutionalism. (pp. 99-129). London: SAGE Publications.

Thornton, P. H., Ocasio, W., \& Lounsbury, M. (2012). The institutional logics perspective: A new approach to culture, structure and process. Oxford, UK: Oxford University Press.

Tracey, P., Phillips, N., \& Jarvis, O. (2011). Bridging institutional entrepreneurship and the creation of new organizational forms: a multilevel model. Organization Science, 22, 60-80.

Wilcox, T. (2012). Human resource management in a compartmentalized world: Whither moral agency? Journal of Business Ethics, 111, 85-96.

Zucker, L. G. (1988). Where do institutional patterns come from? Organizations as actors in social systems. In L. G. Zucker (Ed.), Institutional patterns and organizations: Culture and environment (pp. 23-52). Cambridge, MA: Ballinger.

\section{Author biographies}

Rick Delbridge is professor of organizational analysis, Cardiff Business School and Dean of Research in the College of Arts, Humanities and Social Sciences, Cardiff University. His research interests include work and workplace relations, critical human resource management, the management of innovation and theorizing organization. He has published widely on these and related topics in Academy of Management Review, Human Relations, Journal of Management Studies, Organization Science and Organization Studies. He is currently serving as Associate Editor of Academy of Management Review.

Tim Edwards is a senior lecturer of organizational analysis at Cardiff Business School. His research interests include innovation and knowledge management, organizational institutionalism and relational sociology. He has published on these and related topics in a number of journals including Human Relations, Management Learning and Urban Studies. He is currently serving as Associate Editor for the BAM journal International Journal of Management Reviews. 